\title{
Polypropylene fiber reinforced concrete improved by using silica fume and acrylic emulsion polymer
}

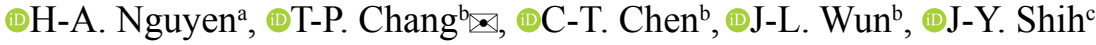 \\ a. Dept. of Rural Technology, College of Rural Development, Cantho University, (Cantho, Vietnam)
b. Dept. of Civil and Construction Engineering, National Taiwan University of Science and Technology, NTUST-Taiwan Tech, (Taipei, \\ Taiwan) \\ c. Dept. of Chemical Engineering, Ming Chi University of Technology, (New Taipei, Taiwan) \\ 『: tpchang@mail.ntust.edu.tw
}

Received 20 March 2021

Accepted 21 July 2021

Available on line 23 February 2022

\begin{abstract}
The current study aims at exploring the beneficial effect of silica fume (SF) and acrylic emulsion polymer (PR) on the enhanced properties of polypropylene fiber reinforced concrete (FRC) with the supplementary cementitious binder comprised of the Portland cement, slag, silica fume and fly ash. The compressive strength and impact-abrasion resistance were used for the estimation of engineering properties while the water absorption performance, surface electricity resistance, and rapid chloride penetration resistance were used for estimation of durability. Experimental results showed that a sole addition of SF increased the compressive strengths but decreased the abrasion-impact resistances of modified FRCs, which was just opposite to the influence of a sole addition of PR. A sole addition of either the SF or PR could moderately improve the durability of modified FRCs, respectively. However, due to the beneficial effect of the complementary interaction between SF and the optimal amount of PR, the mechanical properties and durability of modified FRCs seemed to become significantly improved.
\end{abstract}

KEYWORDS: Concrete; Fly ash; Blast furnace slag; Silica fume; Fiber reinforcement.

Citation/Citar como: Nguyen, H-A.; Chang, T-P.; Chen, C-T.; Wunb, J-L.; Shihc, J-Y. (2022) Polypropylene fiber reinforced concrete improved by using silica fume and acrylic emulsion polymer. Mater. Construcc. 72 [345], e269. https://doi.org/10.3989/ mc.2022.05121.

RESUMEN: Hormigón reforzado con fibra de polipropileno mejorado mediante el uso de humo de sílice y polímero de emulsión acrílica. El estudio tiene como objetivo explorar el efecto beneficioso del humo de sílice (SF) y el polímero de emulsión acrílica (PR) en la mejora de las propiedades del hormigón reforzado con fibra de polipropileno (FRC) y formado por cemento Portland, escoria, humo de sílice y cenizas volantes. La propiedades ingenieriles se evaluaron mediante la caracterización de la resistencia a la compresión y a la abrasión, y las propiedades durables mediante la caracterización de la absorción de agua, la resistencia eléctrica superficial y la resistencia a la penetración rápida del cloruros. Los resultados experimentales mostraron que la adición de SF aumentó la resistencia a la compresión, pero disminuyó la resistencia al impacto-abrasión del FRC modificado, resultado opuesto a lo ocurrido con la adición de PR. La adición única, sea de SF o PR, podría mejorar moderadamente la durabilidad. Sin embargo, debido a la interacción entre SF y PR, tanto las propiedades mecánicas como la durabilidad del FRC modificado parecieron mejorar significativamente.

PALABRAS CLAVE: Hormigón; Cenizas volantes; Escoria de alto horno; Humo de sílice; Refuerzo de fibra.

Copyright: (C2022 CSIC. This is an open-access article distributed under the terms of the Creative Commons Attribution 4.0 International (CC BY 4.0) License. 


\section{INTRODUCTION}

For the past decades, concrete has been one of the most dominant construction materials applied for the sustainable infrastructural construction. When compared with other common construction materials such as steel or aluminum, the concrete structures consume less energy and have the satisfactory mechanical properties and excellent durability (1). However, the existing issues of high energy consumption and tremendous amount of released flue gases induced by the ordinary Portland cement (OPC) manufacture are still observed $(2,3)$. Moreover, the concrete structures with plain OPC illustrate the weak resistances to severe chemical attacks such as the organic acid and sulfate, such that the modern cement/concrete industries need to consider to use the supplementary cementitious material as an alternative binder with multiple enhancements of the final concrete products $(4,5)$.

On the other hand, during the service life, the concrete structures have been vulnerable to the crack issue taking place when the inner tensile stress of concrete members reaches its tensile strength, possibly due to high corrosion potential of the steel rebar $(6,7)$. For the practical reinforced concrete design, the allowable crack sizes have to be limited at a certain threshold dependent on the structural serviceability and environmental attacks (8). By taking the allowable controlled crack into account of concrete structure design, the application of prestressed concrete structure has been a preferable consideration $(9,10)$. However, in some specific situations where the prestressed construction technique is restricted, the enhancement of concrete capacity to restrain the crack occurrence and propagation with an addition of short fiber has become a crucial alternative.

Normally, the type and dosage of fiber are the primary influencing factors to affect the improved performance of a fiber reinforced concrete (FRC) (11) or mortar (12). Recently, various types of steel, glass, synthetic, and natural fibers have been practically used for manufacturing the FRC with significant improvement of bearing capacity and durability to withstand static and dynamic loads $(13,14)$. With the beneficial properties of low specific density and high chemical stability, the synthetic fiber, particularly the polypropylene, or acrylic emulsion polymer (PR) becomes a high level of interest in research (13, 15-18). Currently, the utilization of hybrid fiber for FRC becomes a research interest due to the multiple beneficial effects when compared with the mono FRC $(19,20)$. Although the FRC incorporated with polymer-polymer hybrid fiber has been properly studied $(19,21)$, the study focusing on the performance of FRC with hybrid fiber comprised of acrylic emulsion polymer and polypropylene seems to be relatively limited. For the purpose of gradually enriching the database for the FRC with poly- mer-polymer hybrid fiber, the current study aims at investigating the influence of using the acrylic emulsion polymer on the performance of polypropylene FRC. Moreover, this study further explores the effect of interaction between the high reactive microsilica of silica fume and different amounts of hybrid fiber on the properties of the modified FRC which has not been previously studied.

\section{EXPERIMENTAL PROGRAM}

\subsection{Materials}

The Type I ordinary Portland cement (OPC), ground granulated blast furnace slag (slag), low calcium Class F fly ash (FA), and commercial silica fume (SF) supplied by imported Elkem $940 \mathrm{U}$ were used for the preparation of supplementary cementitious binder. The physicochemical properties of these materials are shown in Table 1. Accordingly, the OPC and slag mostly contained calcium oxide while the FA abundantly contained oxides of aluminum and silicon. On the other hand, the SF distinguished itself with tremendous content of silicon oxide accompanying with minor amount of other oxides. For concrete manufacture, the natural sand with specific gravity of 2.65 and finesse modulus (FM) of 2.72 and the crushed stone with specific gravity of 2.67 and maximum size of $19 \mathrm{~mm}$ were used as fine and coarse aggregates, respectively. The water absorptions of sand and crushed stone were of 1.0 and $0.8 \%$, respectively. The particles size distributions of the aggregates are shown in Figure 1. According to the figure, the aggregates essentially complied with ASTM C33 (22). To produce fiber reinforced concrete (FRC), the commercial polypropylene fiber supplied by the local dealer, Poplar Co. Ltd., Taiwan, with properties shown in Table 2 was used. On the other hand, for preparing the modified FRC with hybrid polymer fiber, the waterborne acrylic polymer used in this study was a domestic commercial product with a trade name of ETERSOL 6976, which was purchased from the Eternal Materials Co., Ltd. Taiwan. It had a cream color, a solid content $\left(150^{\circ} \mathrm{C} \times 15\right.$ mins) of $48 \pm 1 \%$, viscosity (Brookfield, $\mathrm{LVF}$, No, $2,60 \mathrm{rpm}, 30^{\circ} \mathrm{C}$ ) of less than $200 \mathrm{cps}$, a $\mathrm{pH}$ value between 8.0 and 9.0 and a minimum filming temperature $(73 \% \mathrm{RH})$ of 14 to $16^{\circ} \mathrm{C}$. Both polymer and fibers used in this study were available in Taiwan. In this study, commercial Type $G$ superplasticizer (SP) supplied by local dealer, Poplar Co. Ltd., Taiwan (same dealer of polypropylene fiber), was used for achieving the workable concrete. In addition, to minimize the air trapped in the fresh concrete during mixing process, the commercial milky white liquid of antifoam agent supplied by local dealer, Hsin An Instruments Co., Ltd., was also used. 
Polypropylene fiber reinforced concrete improved by using silica fume and acrylic emulsion polymer $\bullet 3$

TABLE 1. Physicochemical properties of OPC and three by-product materials.

\begin{tabular}{lcccc}
\hline Chemical compositions (wt.\%) & OPC & Slag & Class F fly ash (FA) & Silica fume (SF) \\
\hline $\mathrm{SiO}_{2}$ & 20.42 & 34.86 & 49.9 & 88.21 \\
\hline $\mathrm{Al}_{2} \mathrm{O}_{3}$ & 4.95 & 13.52 & 25.6 & 0.33 \\
\hline $\mathrm{Fe}_{2} \mathrm{O}_{3}$ & 3.09 & 0.52 & 3.49 & 0.74 \\
\hline $\mathrm{CaO}$ & 61.96 & 41.77 & 3.63 & 0.93 \\
\hline $\mathrm{MgO}$ & 3.29 & 7.18 & - & 2.37 \\
\hline $\mathrm{SO}_{3}$ & 2.40 & 1.74 & 1.12 & - \\
\hline Loss on ignition & 1.75 & 4.27 & 3.72 & 2.62 \\
\hline Insoluble residue & 1.02 & - & - & - \\
\hline $\mathrm{C}_{3} \mathrm{~S}$ & 49 & - & - & - \\
\hline $\mathrm{C}_{2} \mathrm{~S}$ & 21 & - & - & - \\
\hline $\mathrm{C}_{3} \mathrm{~A}$ & 7.9 & - & - & - \\
\hline $\mathrm{C}_{4} \mathrm{AF}$ & 9.4 & - & - & 2.14 \\
\hline & Physical properties & & - \\
\hline Specific gravity & 3.15 & 2.9 & 2.14 & - \\
\hline Surface area $(\mathrm{cm} / \mathrm{g})$ & 3450 & 6000 & 2630 & - \\
\hline Initial setting $(\mathrm{min})$ & 155 & - & - & - \\
\hline Final setting $(\mathrm{min})$ & 260 & - & & \\
\hline
\end{tabular}

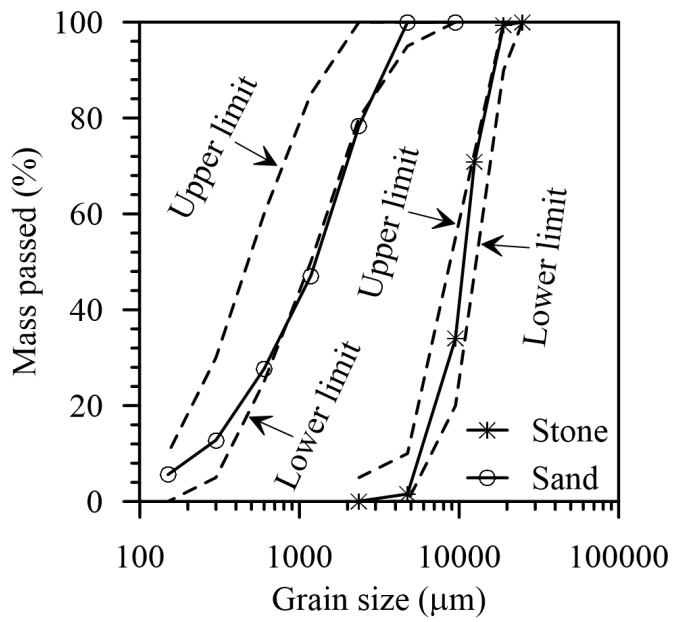

FIGURE 1. Particle size distributions of coarse and fine aggregates.

\subsection{Mix proportions}

The concrete proportions were based on an equivalent fixed volumetric ratio of aggregate to concrete of 0.62 . The mass ratio of fine aggregate to total aggregates was fixed at 0.4 . The reference supplementary cementitious binder contained the ternary mixture of $50 \%$ OPC, $25 \%$ of slag, and $25 \%$ of fly ash in volume. Three amounts of commercial silica fume (SF) were used as partial replacement of OPC with fraction at 0,5 , and $10 \%$ of total volume of the powder, respectively. The commercial polypropylene fiber amount fixed at $0.2 \%$ of concrete volume
TABLE 2. Properties of polypropylene fiber.

\begin{tabular}{ll}
\hline Length, mm & 19 \\
\hline Diameter, mm & 0.36 \\
\hline Specific gravity & 0.9 \\
\hline Tensile strength, MPa & 303 \\
\hline Elastic modulus, GPa & 1.57 \\
\hline Toughness, MPa & 193 \\
\hline Melting point, ${ }^{\circ} \mathrm{C}$ & 225 \\
\hline Appearance & White \\
\hline
\end{tabular}

was used for the control set of FRC. To assess the performance of the modified FRC with hybrid polymer fiber, the commercial acrylic emulsion polymer (PR) was used at 0,5 , and $10 \%$ of total weight of powder. The water to binder ratio $(\mathrm{w} / \mathrm{b})$, in which the water content included both the distilled water and the water extracted from the PR, of all concrete mixtures was fixed at 0.4 . The mix proportions of the concretes are illustrated in Table 3.

\subsection{Specimen preparation and test methods}

The fresh property of concrete was estimated with the slump test in accordance with ASTM C143 (23). Immediately after the slump test, the concrete cyl- 
TABLE 3. Mix proportions for 1 cubic meter of concrete $\left(\mathrm{kg} / \mathrm{m}^{3}\right)$.

\begin{tabular}{lrrrrrrrrrrr}
\hline Mixes & OPC & Slag & FA & SF & PR & PPF & AF $^{*}$ & SP $^{* *}$ & Sand & Stone & Water \\
\hline S0P0 & 266 & 120 & 93 & 0 & 0 & 1.8 & 0 & 0.3 & 654 & 1000 & 191 \\
\hline S0P5 & 266 & 120 & 93 & 0 & 50 & 1.8 & 7.5 & 0.4 & 654 & 1000 & 166 \\
\hline S0P10 & 266 & 120 & 93 & 0 & 100 & 1.8 & 15 & 0.4 & 654 & 1000 & 140 \\
\hline S5P0 & 241 & 121 & 94 & 18 & 0 & 1.8 & 0 & 0.3 & 654 & 1000 & 190 \\
\hline S5P5 & 241 & 121 & 94 & 18 & 49 & 1.8 & 7.5 & 0.4 & 654 & 1000 & 164 \\
\hline S5P10 & 241 & 121 & 94 & 18 & 99 & 1.8 & 15 & 0.5 & 654 & 1000 & 138 \\
\hline S10P0 & 217 & 123 & 95 & 37 & 0 & 1.8 & 0 & 0.4 & 654 & 1000 & 188 \\
\hline S10P5 & 217 & 123 & 95 & 37 & 49 & 1.8 & 7.5 & 0.5 & 654 & 1000 & 163 \\
\hline S10P10 & 217 & 123 & 95 & 37 & 98 & 1.8 & 15 & 0.5 & 654 & 1000 & 137 \\
\hline
\end{tabular}

Note: $\mathrm{OPC}=$ Ordinary Portland cement; FA = Class F fly ash; $\mathrm{SF}=$ Silica fume; $\mathrm{PR}=$ Acrylic emulsion polymer; PPF $=$ Polypropylene fiber; $\mathrm{AF}=$ Antifoam agent; $\mathrm{SP}=$ Superplasticizer; ${ }^{*}$ Mass percent of total fiber; ${ }^{* *}$ Mass percent of total powder.

inders with dimensions of $\phi 100 \times 200 \mathrm{~mm}^{2}$ were cast for the tests of compressive strength in accordance with ASTM C39 (24). The durability of concrete specimen was evaluated by using the tests of water absorption in accordance with ASTM C642 (25), the electricity surface resistance test using 4-point probe equipment, and the rapid chloride penetration test (RCPT) in accordance with ASTM C1202 (26). On the other hand, the $100 \times 100 \times 100 \mathrm{~mm}^{3}$ cubic specimens of concretes were prepared for the abrasion resistance test. After 24 hours, all the concrete specimens were demoulded and cured in room temperature of $23 \pm 2^{\circ} \mathrm{C}$ and relative humidity (RH) of $50-70 \%$ until the ages of testing, without any water curing.

In this study, a self-designed patented enclosed cylindrical steel container of Rotary-drum Hydraulic Impact-Abrasion Testing Machine (US patent $8,833,136 \mathrm{~B} 2$ ) as shown in Figure 2 was used to evaluate the hydraulic impact-abrasion resistance on $100 \times 100 \times 100 \mathrm{~mm}^{3}$ cubic concrete specimens. The testing machine had six $100 \times 100 \mathrm{~mm}^{2}$ openings evenly distributed with an angle of $60^{\circ}$ around its circumferential surface in which each opening allowed a half of one $100 \times 100 \times 100 \mathrm{~mm}^{3}$ cubic concrete specimen to be inserted into the inner compartment of enclosed container which was either filled with water or empty accompanying with 12 steel balls. Thus a half of $100 \times 100 \times 100 \mathrm{~mm}^{3}$ cubic concrete specimen which was inserted into the inner chamber would be subjected to either the wet (container with water) or the dry (container without water) impact and abrasion test simultaneously once the cylindrical container was rotating. One to six $100 \times 100 \times 100 \mathrm{~mm}^{3}$ cubic concrete specimens could be installed for one test. The contacting impact included fixed quantity of uniform steel balls free falling inside the cylindrical steel container. To run the test, the whole system was set to rotate with a fixed speed of 30 to $33 \mathrm{rpm}$ similar to that of ASTM C535-16 for 500 revolutions. The weight loss of $100 \times 100 \times 100 \mathrm{~mm}^{3}$ cubic concrete sample computed after the test was used for estimating the impact-abrasion resistance of concrete mixture. In this study, the impact-abrasion resistances of concrete specimen at both dry and wet conditions were conducted. The wet condition of the test was simulated by filling the enclosed chamber with tap water during the rotating period.

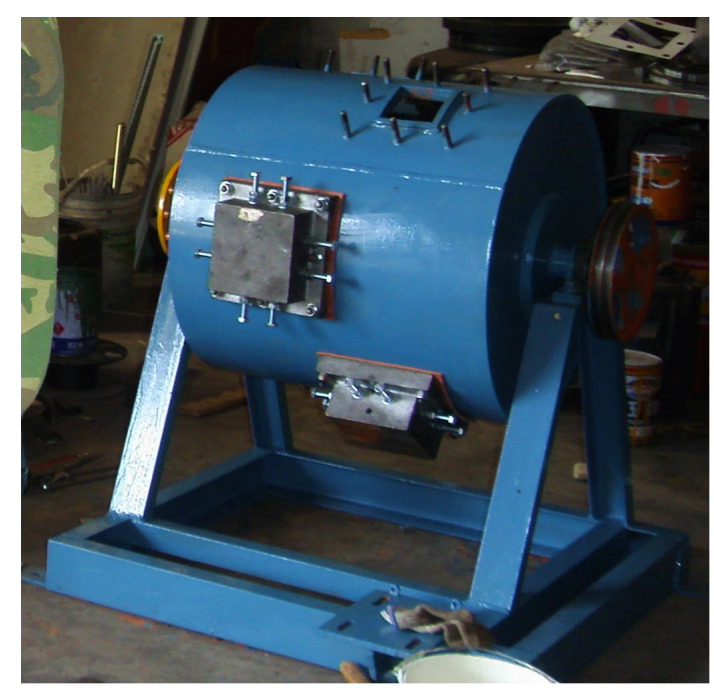

FIGURE 2. Experimental equipment for impact-abrasion test.

In order to continuously measure the water absorption rate of $\phi 100 \times 200 \mathrm{~mm}$ concrete cylinder at time intervals of $0,1,5,10,20,30,60,180$ and 360 minutes, a self-designed experimental cylindrical plastic transparent container with dimension of $\phi 120 \times 210 \mathrm{~mm}^{2}$ was used (Figure 3). After the oven-dried concrete cylinder was set into the cylindrical container, a transparent cap equipped with a vertical graduated capillary tube at the center was sealed to the container. Then the graduated tube 
was used to measure the level of sinking water to estimate the water absorption of oven-dried concrete cylinder after the container being filled with tap water. At beginning of the test, the initial level of added water was recorded and used as the reference value for computing the absorbed water. With the elapse of testing time, the decrease of sinking water level was continuously monitored and used for computing the water absorption and water absorption rate of concrete specimens. In this study, the water absorption rate of concrete was monitored up to initial 6 hours. On the other hand, the final water absorption of concrete specimens was reported after 3 days of immersion.
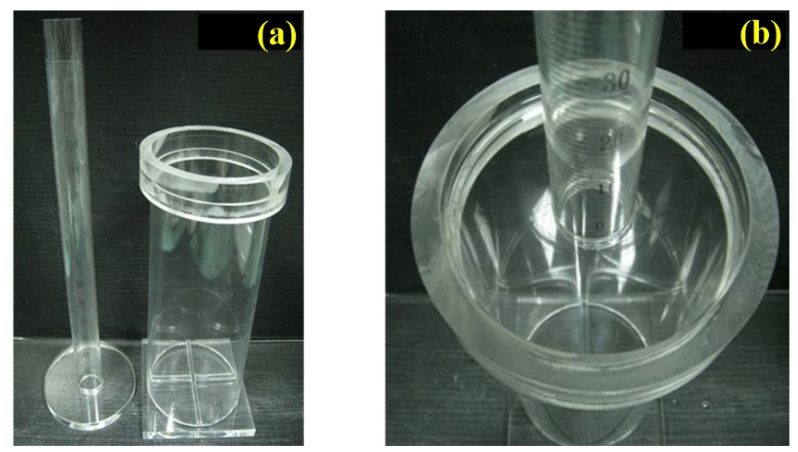

FIGURE 3. Experimental equipment for water absorption test $\left(\phi 120 \times 210\right.$ (a) $\mathrm{mm}^{2}$ for cylindrical container, $\phi 20 \times 300$ (b) $\mathrm{mm}^{2}$ for graduated tube).

The compressive tests of polymer concrete specimens were conducted at ages of 7, 14, 21, 28 and 56 days, respectively, while all the other four tests and the scanning electron microscopic analysis of specimens were performed at age of 28 days.

\section{RESULTS AND DISCUSSIONS}

\subsection{Compressive strength}

The influences of SF and PR on the compressive strengths of the modified FRC specimens are shown in Figure 4 and 5, respectively. Accordingly, the compressive strengths of the concrete specimens increased with the increase of curing ages regardless of the concrete proportions. At the equivalent amount of PR, the compressive strengths of the modified FRC specimens were improved with the increase of SF Figure 4 showed that without using PR, the compressive strengths of modified FRC specimens with $10 \%$ SF were higher than those of the reference FRC specimens without SF addition at all ages of curing. With the increase of PR at 5 and $10 \%$, the compressive strengths of the modified FRC specimens with SF in range of $5-10 \%$ were improved in
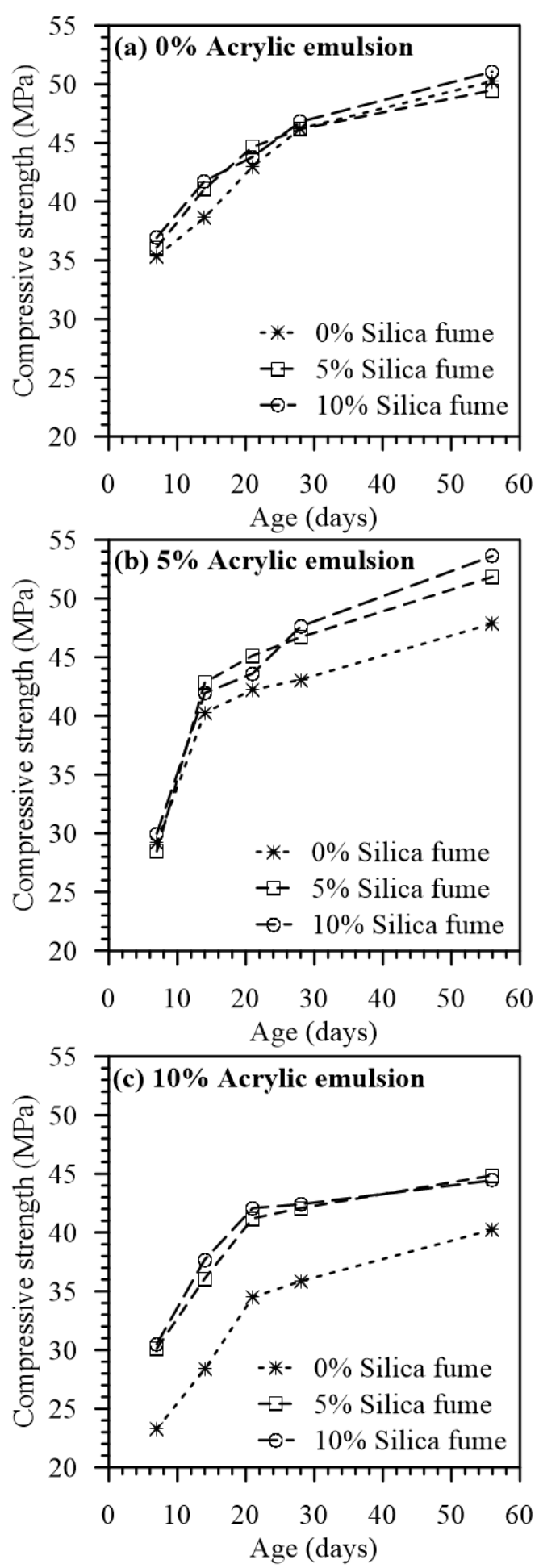

FIGURE 4. Effect of silica fume (SF) on compressive strength of concrete with (a) $0 \%$, (b) $5 \%$ and (c) $10 \%$ of acrylic emulsion.

comparison with those of the control FRC without $\mathrm{SF}$ addition at all ages. The observed results were due to the SF having the pozzolanic property which contributed to the enhancement of pore refinement of binding system induced by the extra hydration 
products. Normally the utilization of silica fume (SF) has a significant improvement on the compressive strength and durability of the hardened concrete with a high amount of Portland cement as the key cementitious agent. As shown in Table 3, the cementitious material for the concrete studied in this study consisted of only $50 \mathrm{vol} . \%$ of Portland cement and other 50 vol.\% of slag, class F fly ash, silica fume and acrylic emulsion polymer. The unique effect by increasing the amount of silica fume from 0 to $10 \%$ on the enhancement of compressive strength of concrete mainly from the pozzolanic reaction seems to be smeared out with the effects from other pozzolanic materials of slag and fly ash and not as apparent as expected. However, the remarkable filling effect of extreme finer size of silica fume as compared with that of slag and fly ash did effectively stuff in the small pores in the microstructure of hydrated cement paste, so that such impressive filling effects of fine silica fume become very significant appeared in the results of water absorption, electrical surface resistance and rapid chloride ingress tests.

On the other hand, the influence of PR addition on the compressive strengths of the modified FRC specimens was minor. Figure 5 showed that irrespective of the SF amount used, the addition of PR significantly reduced the early compressive strengths of modified FRC specimens. Without using SF, the addition of PR illustrated a negative effect on the compressive strengths of the modified FRC specimens at all ages of curing. Consequently, the PR addition normally led to the generation of internal polymerization film causing the reduction of compressive strengths of the modified FRC specimens probably due to the diminished effect of mechanical interlock among the ingredients (27). However, with an addition in range of $5-10 \%$ for both SF and PR, the modified FRC specimens had shown an improvement of compressive strengths after 7 days of curing. Therefore, the addition of SF obviously compensated the negative effect of a sole addition of FR and led to the modified FRC specimens with enhanced compressive strengths at later ages. Such result could be attributed to the improved bonding strength at the interface between the fiber and the high-strength binding matrix (28).

\subsection{Impact-abrasion resistance}

The impact-abrasion resistances of the FRCs with/ without modifiers consisting of SF and/or PR are illustrated in Figure 6, which indicated that a sole addition of SF apparently reduced the impact-abrasion resistance of the modified FRCs. On the contrary, with the addition of SF, the modified FRCs with an addition of PR illustrated the optimal impact-abrasion resistance being superior to that of the FRC without the addition of PR. Such enhanced benefit of
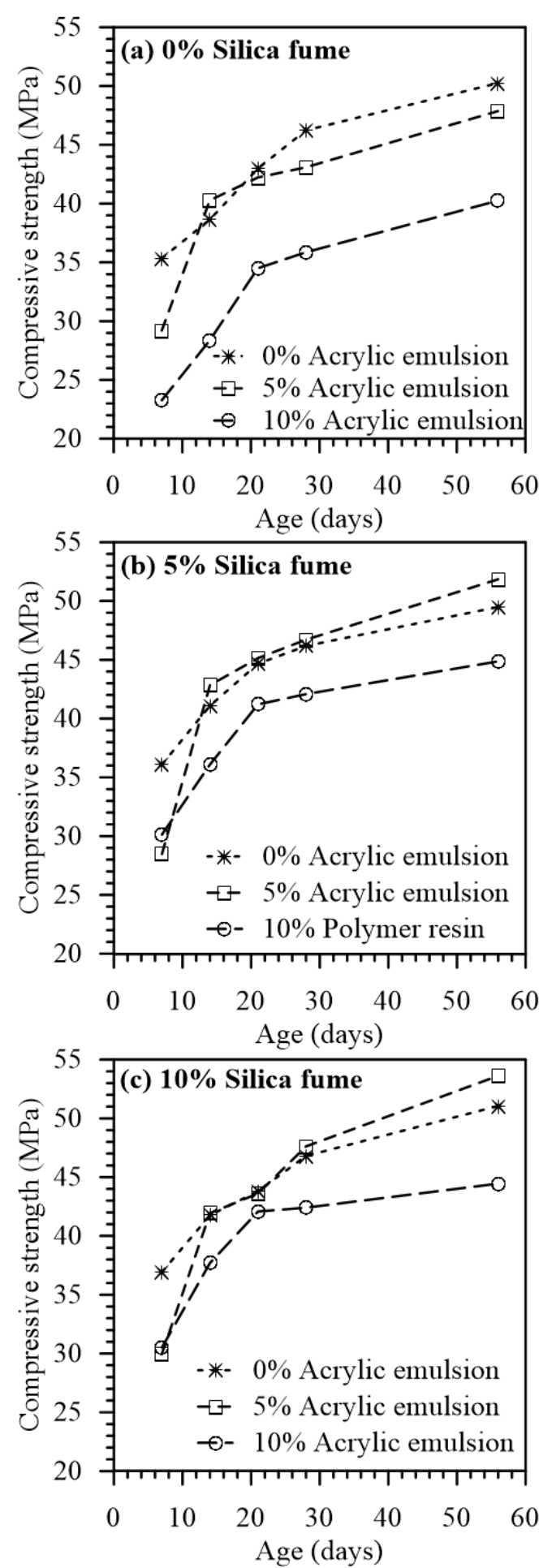

FIGURE 5. Effect of acrylic emulsion polymer (PR) on compressive strength of concrete with (a) $0 \%$, (b) $5 \%$ and (c) $10 \%$ of silica fume.

using the polymer-polymer hybrid fiber to increase the impact-abrasion resistance of FRCs in comparison with a single addition of polypropylene polymer was clearly verified. The usage of SF accompanying 
with the PR resulted in the modified FRCs with a significant enhancement of the impact-abrasion resistance when compared with the SF modified FRCs without the PR addition, implying that the positive effect of the interaction between the SF and PR utilizations on the impact-abrasion resistance of the modified FRCs due to the mutual complementary effect. Figure 6 showed that when compared with the modified FRCs with a sole addition of SF, the modified FRCs with various combinations of SF and PR had the impact-abrasion resistances significantly increased up to $20.1-39.2 \%$ and $4.6-58.7 \%$, respectively, at dry and wet conditions. Regardless of different proportions, the impact-abrasion resistance of FRCs at the wet state was higher than that of the FRCs at dry state. The observed results could be explained due to the lubricating effect from the existence of moisture in the concrete causing the aggregates to slip and separate by each other easily to lower its impact-abrasion resistance. In this study, the addition of SF not only increased the strengths of the modified FRCs but also induced the additional brittleness of binding matrix, which is just opposite to the promoting effect of a sole addition of PR. The increased ductility of FRC in comparison with that of plain concrete was also reported in the previous study (27).

\subsection{Water absorption}

The effects of the SF and/or PR additions on the performance of water absorption of the modified FRCs are investigated in Figure 7, 8 and 9. As can be seen from Figure 7 and 8 , a sole addition of SF or PR significantly reduced the water absorption rate of the modified FRCs during the initial 6 hours. In addition, the beneficial effect of the complementary interaction between the SF and PR additions on the water transport resistance of the modified FRCs was also observed with an exception of the FRCs modified with $5 \% \mathrm{SF}$ and $\mathrm{PR}$ varied in range of $5-10 \%$. Similarly, a sole addition of SF or PR and the complementary interaction between the SF and PR additions induced the modified FRCs with remarkable decrease in water absorptions as shown in Figure 9. In this study, a sole addition of SF in range of 5-10\% and $\mathrm{PR}$ in range of $5-10 \%$ resulted in the modified FRCs with the reduced water absorptions in range of $2.2-7.7 \%$ and $8.8-9.4 \%$, respectively. Such result implied that the beneficial effect of using the PR for reducing the water absorption of the modified FRCs was higher than that of using the SF, which could be due to the waterproof function of the PR to enhance the resistance of modified FRC to the penetration of water molecule. Moreover, the polymer film could be formed in the acrylic emulsion modified concrete specimens subjected to the drying condition, which was probably an additional reason supporting the
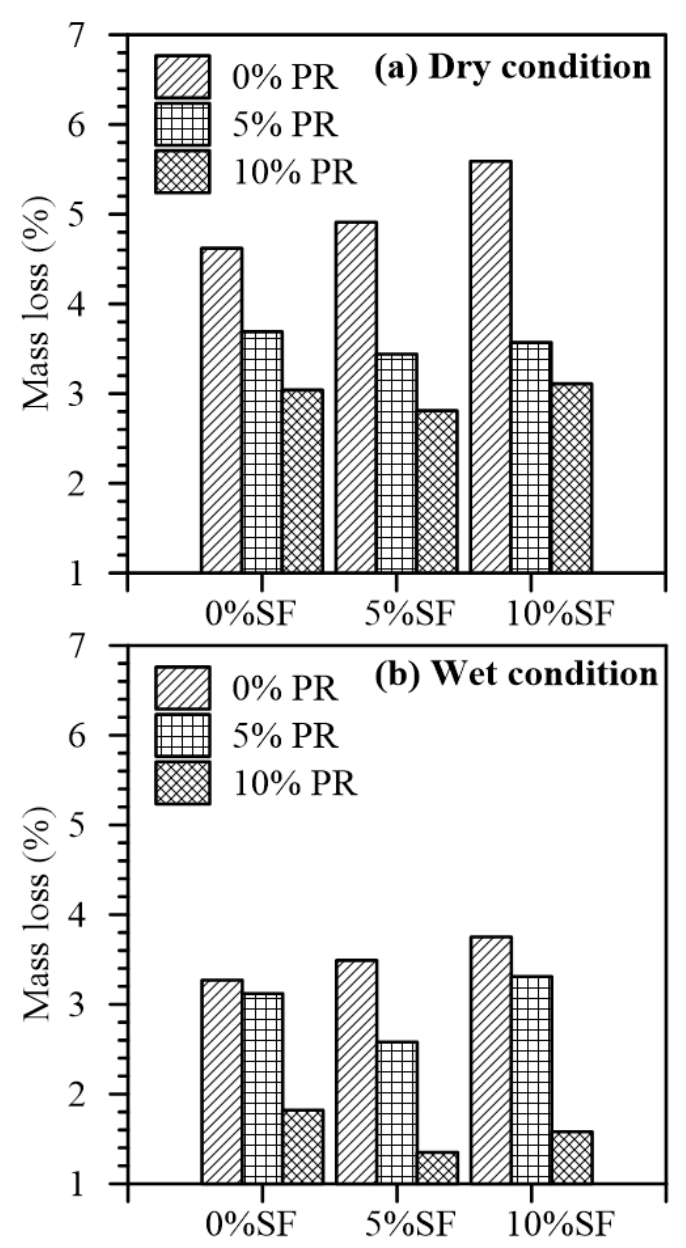

FIGURE 6. Effect of silica fume (SF) and acrylic emulsion polymer (PR) on impact resistance of concrete under (a) dry condition and (b) wet condition.

reduction of water absorption of the acrylic emulsion modified concretes. On the other hand, Figure 9 showed that the advantage of combined addition of SF and PR was better than a sole addition of either SF or PR to improve the water absorption of the modified FRCs. Especially, such beneficial effect obviously was increased with the increase of the amounts of SF and/or PR.

\subsection{Surface electricity resistance}

The surface electricity resistance (SER) has been one of the important indexes used for evaluation of concrete durability in terms of resistance to the ion penetrability through the free water maintained in the pore system. It has been highly agreed that a greater value of SER refers to the concrete with condenser microstructure and thus indicates the higher resistance of concrete to the ion migration. For concrete with a practically acceptable resistance to the permeability, the SER value measured at 56 days of 

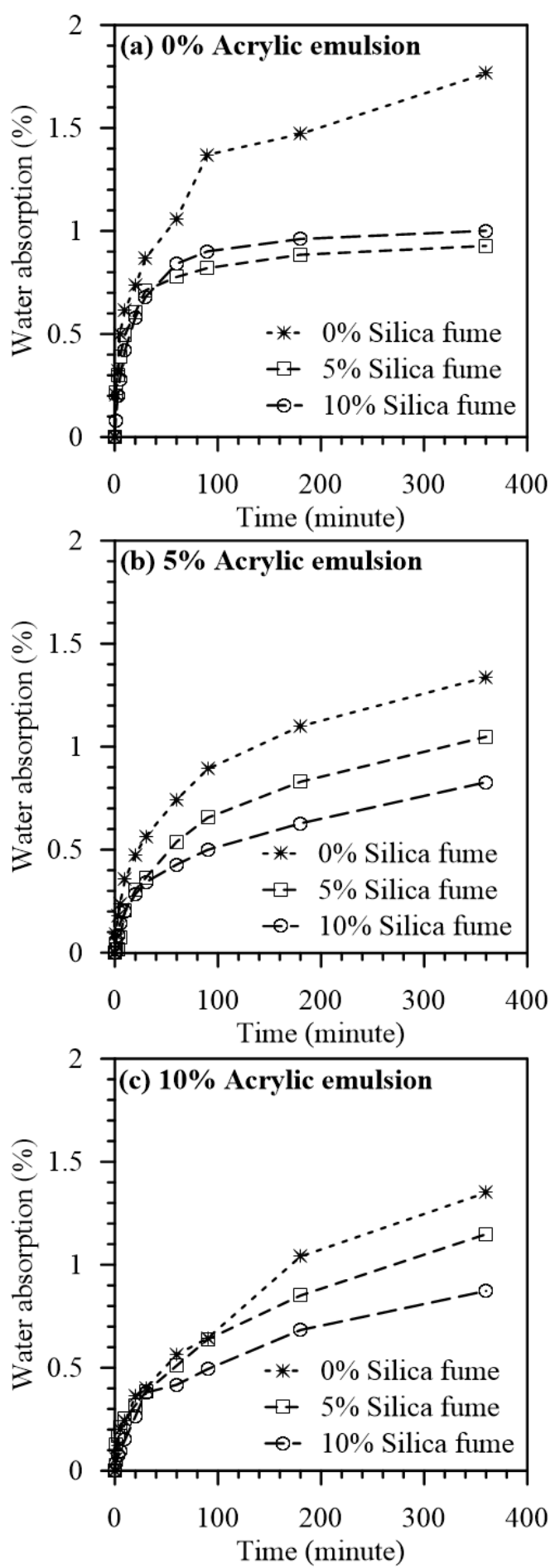

FIGURE 7. Effect of silica fume (SF) on water absorption rate of concrete with (a) $0 \%$, (b) $5 \%$ and (c) $10 \%$ of acrylic emulsion during 6 hours.

curing is normally greater than $200 \Omega-\mathrm{m}(29,30)$. In this study, the SERs of FRCs at ages of up to 56 days were measured as illustrated in Figure 10 and 11. Generally, the SERs of the FRCs increased with the increases of curing ages irrespective of concrete
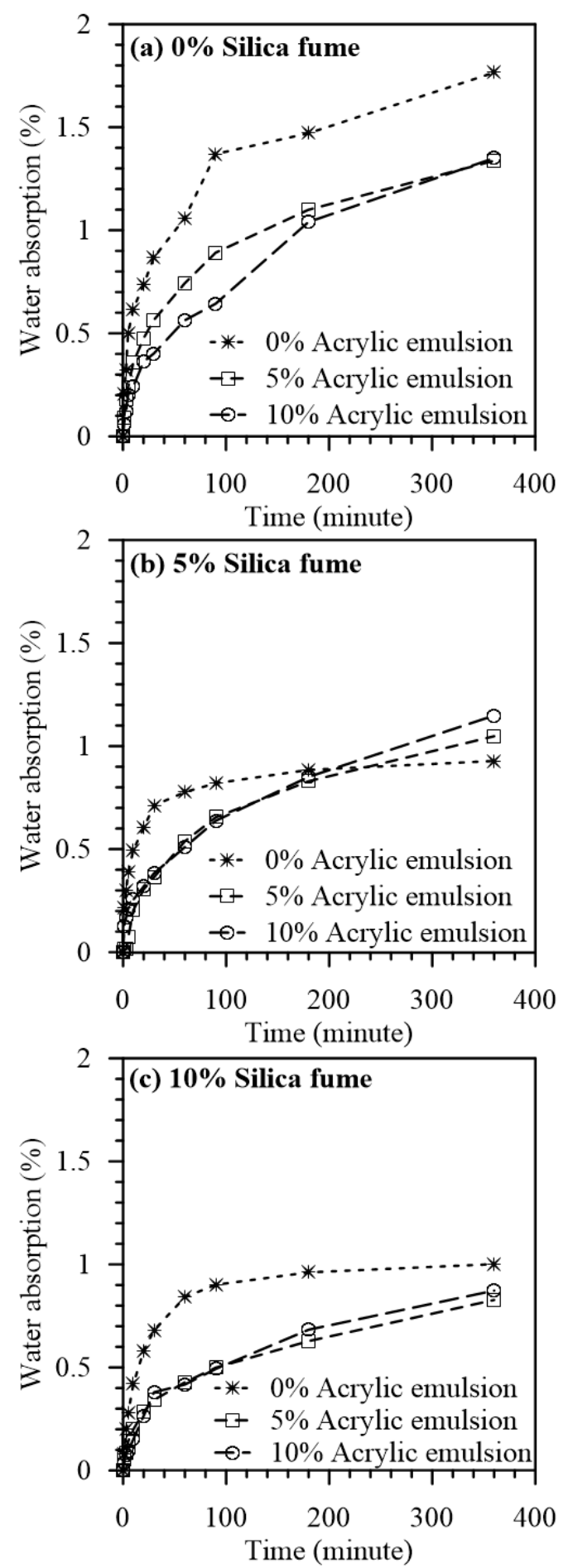

FIGURE 8. Effect of acrylic emulsion polymer (PR) on water absorption rate of concrete with (a) $0 \%$, (b) $5 \%$ and (c) $10 \%$ of silica fume during 6 hours.

proportions. At a specific fixed amount of PR, the SERs of the modified FRCs increased with the addition of SF at all ages when compared with the FRCs without SF addition (Figure 10), which implied that the SF addition significantly improved the permea- 


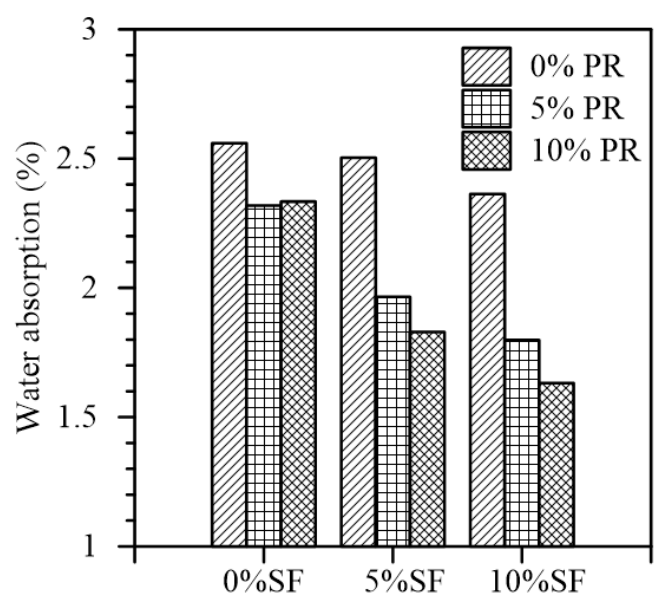

Figure 9. Effect of silica fume (SF) and acrylic emulsion polymer (PR) on water absorption of concrete after $72 \mathrm{~h}$.

bility resistance of the modified FRCs. The reason could result from the improvement of microstructure of the modified FRCs with SF addition due to the acceleration of pozzolanic reaction. Similarly, the values of SER of the modified FRCs increased with the PR addition, which could be due to the low electrical conductivity of the PR. However, the beneficial effect of PR addition was lower than that of the $\mathrm{SF}$ addition, which might reduce the expected advantage of combining additions of SF and PR to increase the permeability resistance of modified FRCs when compared with a sole addition of SF (Figure 10). In this study, all FRCs could be classified as the durable concretes with the satisfactory resistance to the permeability because their SER values at 56-day were higher than the threshold value of $200 \Omega-\mathrm{m}$ as formerly suggested.

\subsection{Rapid chloride penetration test}

Rapid chloride penetration test (RCPT) has been an efficient tool for preliminary estimation of the resistance of concrete to the aggressive ion penetration and thus has been normally applied for predicting the corrosion potential of concrete structure subjected to severe attacks, particularly under the chloride rich environment. In this study, the total charges passing through the FRCs samples detected from the RCPT test are investigated in Figure 12. Accordingly, the SF addition significantly reduced the total charges passing through the modified FRCs with all additions of PR. Figure 12 showed that the reference FRC without an addition of SF and PR had the total passing charges in range of 2000-3000 Coulombs and thus was classified as the concrete with moderate chloride penetrability. An addition of SF at 5\% led to the SF modified FRCs to reduce the total passing charges to a new low range of 1000-2000 Coulombs, which was as-
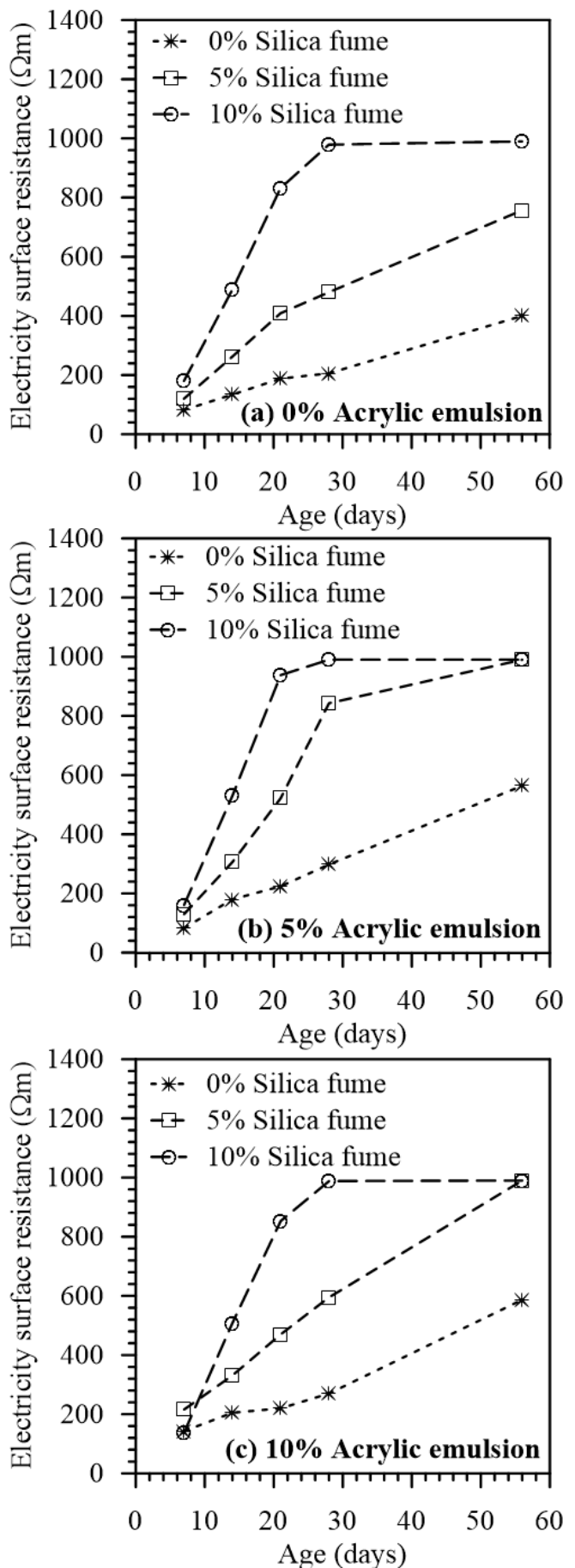

FIGURE 10. Effect of silica fume (SF) on surface resistance to electricity of concrete with (a) $0 \%$, (b) $5 \%$ and (c) $10 \%$ of acrylic emulsion.

sociated with the classification of low chloride penetrability of concrete. Further increase of the SF addition resulted in the SF modified FRCs with the total charges passed to sharply reduce to an even lower range of 100-1000 Coulombs, referring to the concrete with very low chloride penetrability. Similarly, a sole addition of PR also resulted in the 

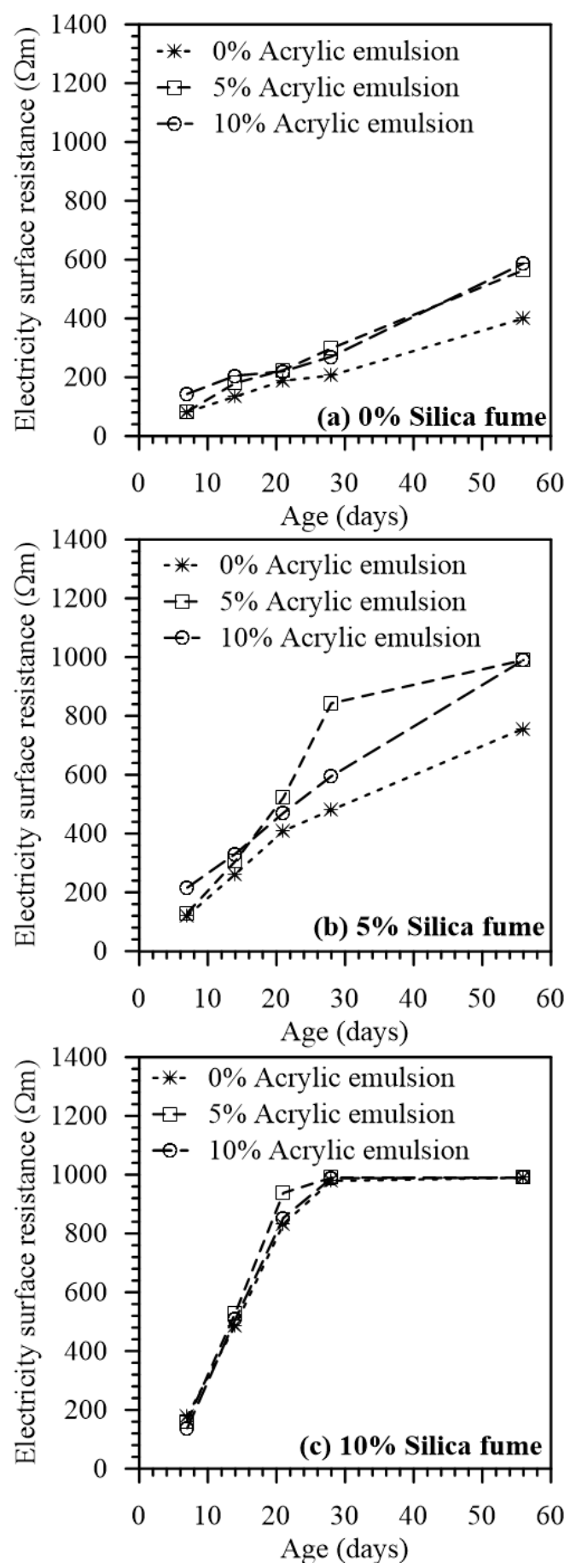

FIGURE 11. Effect of acrylic emulsion polymer (PR) on surface resistance to electricity of concrete with (a) $0 \%$, (b) $5 \%$ and (c) $10 \%$ of silica fume.

PR modified FRCs with a remarkable improvement of the chloride penetration resistivity. According to Figure 12, the modified FRCs with an addition of PR at $10 \%$ was classified as the low chloride penetrability, but the reference FRC without an addition of SF and PR belonged to the moderate chloride penetrability. Moreover, as shown in Figure 12, the most beneficial effect of the modifier on providing the best resistivity of the modified FRCs to the chloride penetrability was the FRC combining the mixture of $10 \% \mathrm{SF}$ and $10 \%$ PR. The literature showed that the microstructure, the chemical composition and the pore solution of concrete have been the crucial factors affecting the RCTP test (31). In this study, the improved resistivity of the SF modified FRCs could be due to the contribution of both the filling effect and pozzolanic reaction of SF powder to pore refinement of the binding matrix. On the other hand, the enhanced resistivity of the modified FRCs with PR was possibly due to the waterproof capacity of the PR.

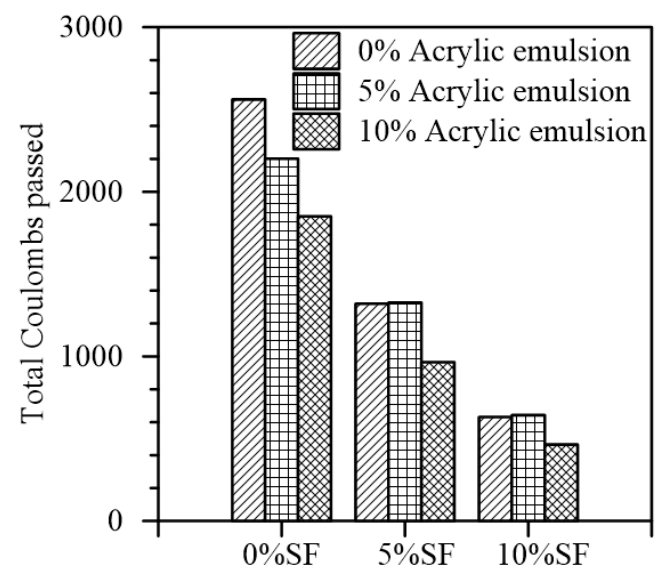

FIGURE 12. Effect of silica fume (SF) and acrylic emulsion polymer (PR) on chloride penetration resistance of concrete.

\subsection{Scanning electron microscope}

The scanning electron microscope (SEM) images of the hardened FRCs modified with SF and PR at 28 days of curing are shown in Figure 13 and Figure 14. Obviously, with a fixed amount of PR, the SF addition induced the modified FRCs with condenser microstructure when comparison with that of the modified FRCs without an addition of SF, which could be due to the extra hydration products supplied from the pozzolanic reaction. On the other hand, with an equivalent amount of SF used, the influence of adding PR on the microstructural condensation of the modified FRCs was invisible. On the other hand, Figure 14 showed that the hydration products of the modified FRCs with the addition of PR seemed to have the surfaces to be smoother than those of the modified FRCs without the PR addition, which could be due to the generation of internal polymerization film of the PR modified FRCs. Therefore, apparently, the SEM images conducted in this study provided proper evidence to support the observed results of mechanical and durability properties of the modified FRCs as formerly discussed. 

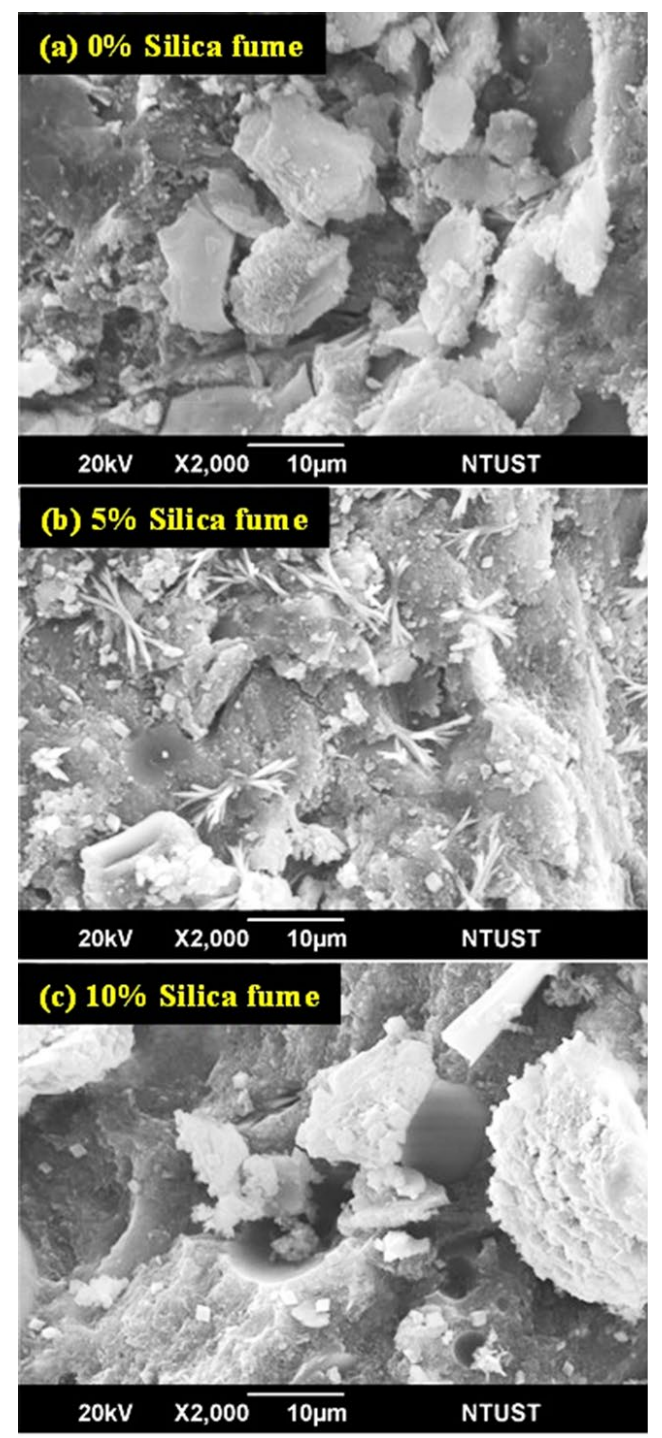

FIGURE 13. Effect of silica fume (SF) on microstructure of concrete with $10 \%$ acrylic emulsion polymer (PR) and with (a) $0 \%$,

(b) $5 \%$ and (c) $10 \%$ of silica fume at 28 days of curing.

\section{CONCLUSIONS}

The influence of utilizations of both the silica fume (SF) and acrylic emulsion polymer (PR) on the engineering and durability performance of the modified fiber reinforced concrete (FRC) with polypropylene fiber has been comprehensively conducted. Experimental results illustrated that a sole addition of SF in range of $5-10 \%$ to replace the ordinary Portland cement significantly increased the compressive strength but decreased the impact-abrasion resistance of the modified FRC. On the contrary, the opposite results were observed for the FRC modified with the PR addition in range of $5-10 \%$. The compressive strengths after 7 days and impact-abrasion resistances at 28 days of the modified FRCs due to the supplemental interaction between the SF and
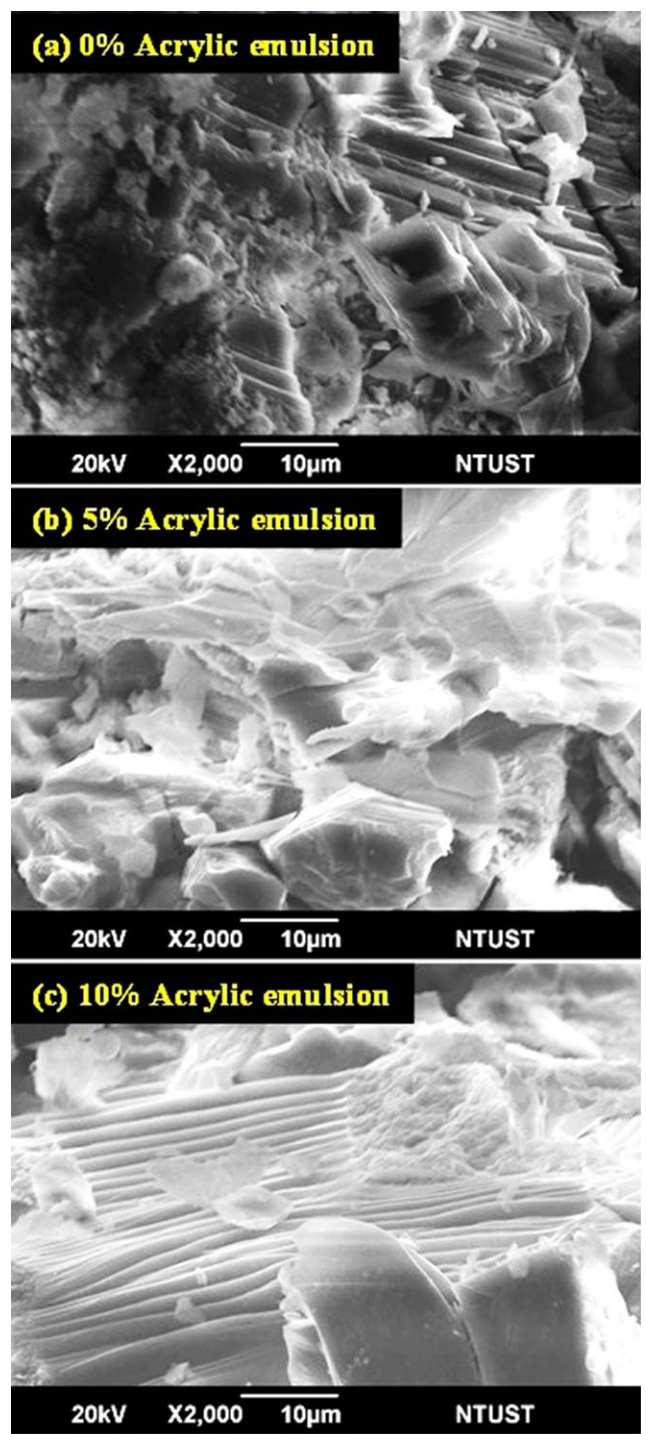

FIGURE 14. Effect of acrylic emulsion polymer (PR) on microstructure of concrete with $10 \%$ silica fume (SF) and with (a) $0 \%$,

(b) $5 \%$ and (c) $10 \%$ of acrylic emulsion at 28 days of curing.

PR additions were higher than those of the reference FRC, respectively. Sole additions of either the SF in range of $5-10 \%$ or the PR in range of $5-10 \%$ increased the durability of the modified FRCs in terms of the reduced water absorption rate and the reduced water absorption, increased the surface electricity resistance (SER), and reduced total charges passing through concrete specimens. Improvements of durability of the modified FRCs with interaction between SF and PR additions were also observed. In this study, the modified FRC with $10 \% \mathrm{SF}$ and $10 \%$ PR had the lowest water absorption, the highest SER value at 28 days of curing, and the lowest total charges passed at 56 days of curing, which were $36.2 \%$ lower, 12.1 times higher, and 5.5 times lower than those of the reference FRC without the addition of SF and PR, respectively. 


\section{ACKNOWLEDGEMENTS}

The authors would like to acknowledge the financial aid from the National Taiwan University of Science and Technology (NTUST) (Taiwan Tech) and the Ministry of Science and Technology, Taiwan, R.O.C. through research grants of 103-2221-E-011-078-MY3 and 107-2221-E-011073 and National Foundation for Science and Technology Development (NAFOSTED), Vietnam, through research grant of 107.99-2018.301 for this investigation.

\section{AUTHOR CONTRIBUTIONS:}

Conceptualization: T-P. Chang. Data curation: J-L. Wun. Formal analysis: C-T. Chen. Investigation: J-L. Wun. Methodology: H-A. Nguyen. Resources: J-Y. Shih. Validation: J-Y. Shih. Visualization: C-T. Chen. Roles/Writing, original draft: H-A. Nguyen. Writing, review \& editing: T-P. Chang.

\section{REFERENCES}

1. Gutowski Timothy, G.; Sahni, S.; Allwood Julian, M.; Ashby Michael, F.; Worrell, E. (2013) The energy required to produce materials: constraints on energy-intensity improvements, parameters of demand. Philos. Trans. R. Soc. London, Ser. A. 371 [1986], 20120003. https://doi.org/10.1098/rsta.2012.0003.

2. Talaei, A.; Pier, D.; Iyer, A. V.; Ahiduzzaman, M.; Kumar, A. (2019) Assessment of long-term energy efficiency improvement and greenhouse gas emissions mitigation options for the cement industry. Energy. 170, 1051-1066. https://doi.org/10.1016/j.energy.2018.12.088.

3. Rust, D.; Rathbone, R.; Mahboub Kamyar, C.; Robl, T. (2012) Formulating low-energy cement products. J. Mater. Civ. Eng. 24 [9], 1125-1131. https://doi.org/10.1061/(ASCE) MT.1943-5533.0000456.

4. Damtoft, J.S.; Lukasik, J.; Herfort, D.; Sorrentino, D.; Gartner, E.M. (2008) Sustainable development and climate change initiatives. Cem. Concr. Res. 38 [2], 115-127. https:// doi.org/10.1016/j.cemconres.2007.09.008

5. Juenger, M.C.G.; Winnefeld, F.; Provis, J.L.; Ideker, J.H. (2011) Advances in alternative cementitious binders. Cem. Concr. Res. 41 [12], 1232-1243. https://doi.org/10.1016/j. cemconres.2010.11.012.

6. Pal Kaur, N.; Kumar Shah, J.; Majhi, S.; Mukherjee, A. (2019) Healing and simultaneous ultrasonic monitoring of cracks in concrete. Mater. Today Commun. 18, 87-99. https:// doi.org/10.1016/j.mtcomm.2018.10.022.

7. Lang, L.; Zhu, Z.; Zhang, X.; Qiu, H.; Zhou, C. (2019) Investigation of crack dynamic parameters and crack arresting technique in concrete under impacts. Constr. Build. Mater. 199, 321-334. https://doi.org/10.1016/j. conbuildmat.2018.12.029.

8. Marí, A.; Torres, L.; Oller, E.; Barris, C. (2019) Performancebased slenderness limits for deformations and crack control of reinforced concrete flexural members. Eng. Struct. 187, 267-279. https://doi.org/10.1016/j.engstruct.2019.02.045.

9. Farnam, S.M.; Rezaie, F. (2019) Simulation of crack propagation in prestressed concrete sleepers by fracture mechanics. Eng. Fail. Anal. 96, 109-117. https://doi. org/10.1016/j.engfailanal.2018.09.012.

10. Murray, C.D.; Diaz-Arancibia, M.; Okumus, P.; Floyd, R.W. (2019) Destructive testing and computer modeling of a scale prestressed concrete I-girder bridge. Eng. Struct. 183, 195205. https://doi.org/10.1016/j.engstruct.2019.01.018.

11. Yoo, D.-Y.; Banthia, N. (2019) Impact resistance of fiberreinforced concrete - A review. Cem. Concr. Compos. 104, 103389. https://doi.org/10.1016/j.cemconcomp.2019.103389.
12. Bustos, A.; Moreno, E.; González, F.; Cobo, A. (2020) Influence of the addition of carbon fibers on the properties of hydraulic lime mortars: comparison with glass and basalt fibers. Mater. Construcc. 70 [340], e229. https://doi. org $/ 10.3989 / \mathrm{mc} .2020 .00120$.

13. Alhozaimy,A.M.; Soroushian, P.; Mirza,F.(1996) Mechanical properties of polypropylene fiber reinforced concrete and the effects of pozzolanic materials. Cem. Concr. Compos. 18 [2], 85-92. https://doi.org/10.1016/0958-9465(95)00003-8.

14. Reis, J.M.L. (2006) Fracture and flexural characterization of natural fiber-reinforced polymer concrete. Constr. Build. Mater. 20 [9], 673-678. https://doi.org/10.1016/j. conbuildmat.2005.02.008

15. Qin, Y.; Zhang, X.; Chai, J.; Xu, Z.; Li, S. (2019) Experimental study of compressive behavior of polypropylene-fiberreinforced and polypropylene-fiber-fabric-reinforced concrete. Constr. Build. Mater. 194, 216-225. https://doi. org/10.1016/j.conbuildmat.2018.11.042.

16. Saje, D.; Bandelj, B.; Šušteršič, J.; Lopatič, J.; Saje, F. (2011) Shrinkage of polypropylene fiber-reinforced highperformance concrete. J. Mater. Civ. Eng. 23 [7], 941-952. https://doi.org/10.1061/(ASCE)MT.1943-5533.0000258.

17. Saeedian, A.; Dehestani, M.; Asadollahi, S.; Vaseghi Amiri, J. (2017) Effect of specimen size on the compressive behavior of self-consolidating concrete containing polypropylene fibers. J. Mater. Civ. Eng. 29 [11], 04017208. https://doi. org/10.1061/(ASCE)MT.1943-5533.0002067.

18. Ríos José, D.; Cifuentes, H.; Leiva, C.; García, C.; Alba María, D. (2018) Behavior of high-strength polypropylene fiber-reinforced self-compacting concrete exposed to high temperatures. J. Mater. Civ. Eng. 30 [11], 04018271. https:// doi.org/10.1061/(ASCE)MT.1943-5533.0002491.

19. Pakravan, H.R.; Latifi, M.; Jamshidi, M. (2017) Hybrid short fiber reinforcement system in concrete: A review. Constr. Build. Mater. 142, 280-294. https://doi.org/10.1016/j. conbuildmat.2017.03.059.

20. Siva Chidambaram, R.; Agarwal, P. (2015) Seismic behavior of hybrid fiber reinforced cementitious composite beam-column joints. Mater. Des. 86, 771-781. https://doi. org/10.1016/j.matdes.2015.07.164.

21. Leung, H.Y.; Balendran, R.V. (2003) Properties of fresh polypropylene fibre reinforced concrete under the influence of pozzolans. J. Civ. Eng. Manage. 9 [4], 271-279. https://doi. org/10.1080/13923730.2003.10531339.

22. ASTM (2018) Standard specification for concrete aggregates. ASTM C33. West Conshohocken, PA

23. ASTM (2015) Standard test method for slump of hydrauliccement concrete. ASTM C143. West Conshohocken, PA.

24. ASTM (2018) Standard test method for compressive strength of cylindrical concrete specimens. ASTM C39. West Conshohocken, PA.

25. ASTM (2013) Standard test method for density, absorption, and voids in hardened concrete. ASTM C642. West Conshohocken, PA.

26. ASTM (2019) Standard test method for electrical indication of concrete's ability to resist chloride ion penetration. ASTM C1202. West Conshohocken, PA.

27. Morin, V.; Moevus, M.; Dubois-Brugger, I.; Gartner, E. (2011) Effect of polymer modification of the paste-aggregate interface on the mechanical properties of concretes. Cem. Concr. Res. 41 [5], 459-466. https://doi.org/10.1016/j. cemconres.2011.01.006.

28. Zhang, Y.; Yan, L.; Wang, S.; Xu, M. (2019) Impact of twisting high-performance polyethylene fibre bundle reinforcements on the mechanical characteristics of high-strength concrete. Mater. Construcc. 69 [334], e184. https://doi.org/10.3989/ mc.2019.01418.

29. Ghosh, P.; Tran, Q. (2015) Correlation between bulk and surface resistivity of concrete. Int. J. Concr. Struct. Mater. 9 [1], 119-132. https://doi.org/10.1007/s40069-014-0094-z.

30. FDOT (2004) Florida method of test for concrete resistivity as an electrical indicator of its permeability. Standard FM5578. Florida Department of Transportation.

31. Wee, T.H.; Suryavanshi, A.K.; Tin, S.S. (2000) Evaluation of rapid chloride permeability test (RCPT) Results for concrete containing mineral admixtures. ACI Mater. J. 97 [2], 221-232. 